\title{
Avaliação microbiológica de cones de guta-percha: estudo in vitro
}

Evaluación microbiológica de conos de guta percha: estudio in vitro

Microbiological assessment of cones of guta-percha: study in vitro Mariana Ramos GUEDES ${ }^{1}$

Péricles Natanael Fernandes de MEDEIROS ${ }^{2}$

Mayanne Leite da COSTA $^{2}$

Ingryd Sales MORAIS ${ }^{2}$

Jessica Lucena FREITAS ${ }^{1}$

Gabriel Leite Rafael de ARAGÃO ${ }^{1}$

José Henrique de Araújo CRUZ ${ }^{3}$

Priscila Medeiros BEZERRA ${ }^{4}$

Paula Vanessa da SILVA ${ }^{5}$

${ }^{1}$ Cirurgiã(o)-Dentista. Departamento de Odontologia, Centro Universitário - UNIFIP 58704-000 Patos/PB, Brasil

${ }^{2}$ Acadêmico(a) do Curso de Graduação em Odontologia. Departamento de Odontologia, Centro Universitário - UNIFIP 58704-000 Patos/PB, Brasil

${ }^{3}$ Cirurgiã(o)-Dentista. Centro de Saúde e Tecnologia Rural, Universidade Federal de Campina Grande, UFCG 58708-110 Patos/PB, Brasil

${ }^{4}$ Professora Mestre do Curso de Graduação em Odontologia. Departamento em Odontologia, Faculdades Integradas de Patos, FIP 58416-440 Campina Grande-PB, Brasil

${ }^{5}$ Professora Doutora do Curso de Graduação em Odontologia. Departamento em Odontologia, Faculdades Integradas de Patos, FIP 58416-440 Campina Grande-PB, Brasil

\section{Resumo}

A maior causa da necessidade de retratamento endodôntico é a resistência microbiana ao preparo químico-mecânico e aos materiais obturadores. Sendo importante avaliar o padrão de desinfecção dos cones de guta-percha utilizadas na obturação endodôntica, para que se obtenha a máxima desinfecção durante o tratamento. O objetivo do presente trabalho foi verificar a desinfecção dos cones de guta-percha utilizados na obturação endodôntica através de um estudo in vitro. Para tal, utilizou-se a seguinte metodologia: a amostra foi constituída por 45 cones de guta-percha, da $2^{\circ}$ série (Dentsply®), dividida em duas coletas, uma inicial e outra final, a qual foi dividida em três grupos G1 (água destilada), G2 (hipoclorito de sódio) e G3 (clorexidina). Em cada grupo, foi utilizada uma substância de desinfecção, exceto no G1 (grupo controle). Inicialmente a análise foi realizada para verificar a esterilização dos cones em embalagens lacradas e posteriormente verificar a redução de microrganismos presentes nos cones de guta-percha, após o uso das soluções desinfectante. Os resultados dessa pesquisa evidenciaram que mesmo embalagens lacradas podem apresentar insucesso na esterilização dos cones, e que soluções de Hipoclorito de Sódio 2,5\% e Clorexidina $2 \%$ foram eficazes em $75 \%$ dos casos, na desinfecção dos cones de guta-percha. Concluiu-se que, é necessária a desinfecção dos cones de guta-percha apesar de serem conduzidos em condições assépticas, e que ambas as soluções desinfectante foram eficazes na descontaminação prévia dos cones de guta-percha.

Descritores: Endodontia; Guta-Percha; Desinfecção.

\section{Abstract}

The major cause of the need for endodontic retreatment is microbial resistance to chemical-mechanical preparation and sealing materials. It is important to evaluate the disinfection pattern of gutta-percha cones used in endodontic obturation, in order to obtain maximum disinfection during treatment. The objective of the present work was to verify the disinfection of gutta-percha cones used in endodontic obturation through an in vitro study. For this, the following methodology was used: the sample consisted of 45 cones of gutta-percha, from the 2 st series (Dentsply®), divided into two collections, one initial and one final, which was divided into three groups G1 (distilled water), G2 (sodium hypochlorite) and G3 (chlorhexidine). In each group, a disinfection substance was used, except in G1 (control group). Initially the analysis was to verify the sterilization of the cones in sealed packages and later to verify the reduction of microorganisms present in the cones of gutta-percha, after the use of the disinfectant solutions. The results showed that even sealed packages may fail to sterilize the cones, and that solutions of $2.5 \%$ Sodium Hypochlorite and $2 \%$ Chlorhexidine were effective in $75 \%$ of the cases in the disinfection of gutta-percha cones. It was concluded that disinfection of gutta-percha cones is required despite being conducted under aseptic conditions, and that both disinfecting solutions were effective in the prior decontamination of gutta-percha cones.

Descriptors: Endodontics; Gutta-Percha; Desinfection.

\section{Resumen}

La causa principal de la necesidad de retratamiento endodóntico es la resistencia microbiana a la preparación químicomecánica y a los materiales obturadores. Es importante evaluar el patrón de desinfección de los conos de gutapercha utilizados en la obturación endodóntica, de modo que se pueda obtener la máxima desinfección durante el tratamiento. El objetivo del presente estudio fue verificar la desinfección de los conos de gutapercha utilizados en la obturación endodóntica a través de un estudio in vitro. Para esto, se utilizó la siguiente metodología: la muestra consistió en 45 conos de gutapercha de segundo grado (Dentsply®), divididos en dos colecciones, una inicial y una final, que se dividió en tres grupos. G1 (agua destilada), G2 (hipoclorito de sodio) y G3 (clorhexidina). En cada grupo, se utilizó una sustancia desinfectante, excepto en G1 (grupo control). Inicialmente, el análisis se realizó para verificar la esterilización de los conos en paquetes sellados y luego para verificar la reducción de microorganismos presentes en los conos de gutapercha después del uso de soluciones desinfectantes. Los resultados de esta investigación mostraron que incluso los paquetes sellados pueden haber fallado la esterilización de los conos, y que las soluciones de hipoclorito de sodio al $2.5 \%$ y clorhexidina al $2 \%$ fueron efectivas en el $75 \%$ de los casos en la desinfección de conos de gutapercha. Se concluyó que la desinfección de los conos de gutapercha es necesaria a pesar de realizarse bajo condiciones asépticas, y que ambas soluciones desinfectantes fueron efectivas en la descontaminación previa de los conos de gutapercha.

Descriptores: Endodoncia; Gutta-Percha; Desinfección.

INTRODUÇÃO

A endodontia é a especialidade da Odontologia que se atém ao estudo da anatomia, fisiologia e das patologias relacionadas à polpa dentária, bem como o tratamento das doenças que acometem esse componente do órgão dental. O tratamento do sistema de canais radiculares é um recurso de primordial importância na manutenção de dentes com comprometimento pulpar ${ }^{1}$. Um dos principais objetivos do 
tratamento endodôntico é a desinfecção do sistema de canais radiculares através da eliminação e/ ou redução de microrganismos. Todo este processo depende de uma cadeia asséptica realizada antes, durante e após o tratamento endodôntico, favorecendo assim o sucesso da terapia, através do reparo biológico².

O protocolo clínico usado na Endodontia consiste em várias etapas. A primeira delas é determinar o diagnóstico a partir de uma anamnese bem feita, exame físico-extra e intra oral e exame radiográfico, sendo este último fundamental. Após o estabelecimento do diagnóstico é realizada a cavidade de acesso coronário, em seguida, a exploração do canal e o preparo químico-mecânico. Por fim, realiza-se a obturação endodôntica, através da técnica da condensação lateral utilizando cones de guta percha $^{3}$.

De acordo com Fagundes et al. $^{4}$, a obturação do sistema de canais radiculares tem a finalidade de isolar o meio interno do externo, impedindo a passagem de fluidos e bactérias provenientes da cavidade oral à região periapical. Alcançado este objetivo, a obturação vai apresentar um importante papel tendo três principais funções: sepultar os microorganismos que possam ter resistido ao preparo, bloquear o influxo de fluido do tecido periapical e evitar a infiltração microbiana coronária.

Apesar dos cones de guta-percha serem confeccionados sob condições assépticas, eles podem ser contaminados através do manuseio, aerossóis e forças físicas durante o processo de estocagem. Devido suas características termoplásticas e por ser um material de baixa fusão, a guta-percha não pode ser esterilizada em autoclaves ou por métodos de alta temperatura, porque esses procedimentos causariam deformações em sua estrutura. Dessa forma, outros métodos de desinfecção química rápida devem estar disponíveis nos consultórios 5 .

É importante que se avalie o padrão de desinfecção dos cones de guta-percha utilizados na obturação endodôntica, para que se obtenha a máxima desinfecção possível durante o tratamento endodôntico. Portanto, objetivou-se verificar a desinfecção dos cones de guta-percha utilizados na obturação endodôntica através de um estudo in vitro.

MATERIAL E MÉTODO

Trata-se de estudo laboratorial, experimental e descritivo tendo como um dos seus objetivos identificar problemas a serem estudados através de métodos analíticos e sugerir áreas de interesse para investigação. Foi realizado no laboratório de Microbiologia das Ciências básicas de saúde das Faculdades Integradas de Patos-FIP / PB no período de agosto a novembro de 2017.

O universo foi composto por cones de guta-percha, cuja amostra foi formada por 45 cones da segunda série, de diâmetro 50 , Dentsply ${ }^{\circledR}$, que apresentaram 0 mesmo comprimento, divididos em 3 grupos, com 15 cones em cada. $O$ cálculo do tamanho da amostra foi feito levando em consideração o desenho metodológico do tipo experimental e as estimativas iniciais do desfecho principal (crescimento de microrganismos) obtidas a partir do estudo piloto, adotando os seguintes parâmetros: nível de significância de 5\% ( $\alpha=$ $0,05)$, intervalo de confiança de $95 \%$, poder estatístico de $99 \%(\beta=0,01)$ e razão de alocação dos espécimes nos grupos de substâncias testadas de 1:1, indicando a necessidade de incluir 15 espécimes em cada grupo ${ }^{6}$. O software $G^{*}$ Power (versão 3.1 ) foi usado para realizar o cálculo do tamanho da amostra. Foram incluídos os cones de gutapercha de diâmetro 50, que possuíam o mesmo comprimento. Sendo excluídos os cones de guta-percha de diâmetro 50 que apresentaram comprimentos variados e os cones de demais diâmetros do padrão ISO. Todo o procedimento foi realizado em câmara de fluxo laminar (Quimis, Diadema, SP, Brasil), próximo à chama do bico de Bunsen, para evitar a contaminação cruzada do meio externo. Sendo realizadas duas coletas microbiológicas:

\section{- Coleta Inicial}

Inicialmente os cones de guta-percha foram retirados das caixas com o auxílio de uma pinça clínica estéril, sendo feito o plaqueamento através da técnica de Maki (Com a ponta do cateter aquecida sob à chama do bico de Bunsen, fez-se o rolamento dos cones que foram retirados da caixa lacrada e posicionados imediatamente nas placas de Petri contendo Agár Mueller-Hinton (agár sangue de carneiro a $8 \%$ ) (Figura 1). Estes foram levados à estufa bacteriológica (Quimis, Diadema, SP, Brasil) a $37^{\circ} \mathrm{C}$ e atmosfera de $10 \%$ de $\mathrm{CO}_{2}$ por um período de 24 a $72 \mathrm{~h}$. Sendo possível a avaliação de bactérias em $24 \mathrm{~h}$ e de fungos em 72h. Após esse período, as colônias de microrganismos que estavam presentes nas placas, foram analisadas microbiologicamente $e$ identificadas para verificação dos tipos de microrganismos presentes nos cones de gutapercha (Tabela 1). 


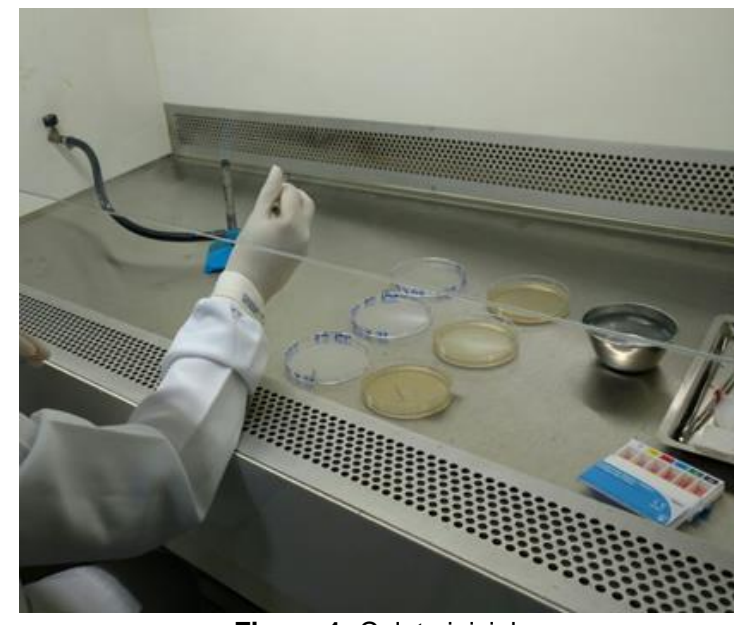

Figura 1: Coleta inicial.

Tabela 1. Distribuição dos espécimes (n) por grupo de acordo com a substância utilizadapara desinfecção dos cones de guta-percha

\begin{tabular}{c|c|c}
\hline GRUPOS & $\begin{array}{c}\text { SOLUÇÕES } \\
\text { IRRIGADORAS }\end{array}$ & ESPÉCIMES (n) \\
\hline Grupo1 (Controle) & Água Destilada & 15 \\
\hline Grupo 2 & NaOCl a 2,5\% & 15 \\
\hline Grupo 3 & Clorexidina líquida 2\% & 15 \\
\hline
\end{tabular}

\section{- Coleta Final}

Após a divisão dos grupos, cada grupo, de acordo com a substância utilizada na desinfecção dos cones, foi imerso em uma cuba contendo a solução desinfectante por um período de 3 minutos. Posteriormente, os cones foram removidos com o auxílio de uma pinça clínica estéril e secos em gaze estéril.

Após os cones serem secos em gaze estéril, foram colocados em placas contendo Agár Mueller-Hinton (agár sangue de carneiro a $8 \%$ ) sendo executada a técnica de Maki (Figura 2). As placas foram levadas à estufa bacteriológica (Quimis, Diadema, SP, Brasil) a $37^{\circ} \mathrm{C}$ e atmosfera de $10 \%$ de $\mathrm{CO}_{2}$ por um período de 24 a $72 \mathrm{~h}$. Após esse período, as placas foram analisadas microbiologicamente para a verificação da possível redução dos microrganismos presentes nos cones de gutapercha, após a utilização das soluções desinfectantes.

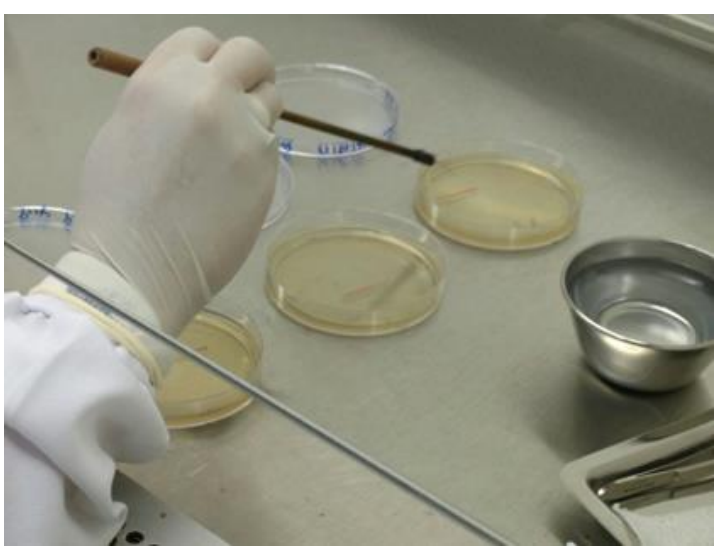

Figura 2: Técnica de Maki.
Em 2002, Soares e Ribeiro ${ }^{7}$ descreveram o método de Gram (segue o passo a passo):

- Preparo do esfregaço

1. Pegou-se uma lâmina limpa no recipiente, secou-a e flambou-a rapidamente na chama do bico de Bunsen.

2. Identificou-se o lado da lâmina onde será feito o esfregaço;

3. Flambou a alça bacteriológica e deixou esfriar para colocar na lâmina uma gota de solução salina fisiológica;

4. Flambou a agulha bacteriológica, deixando esfriar próximo a chama, abriu a placa com a cultura teste e tonou na colônia escolhida para retirada da amostra;

5. Esfregou-se o material com movimentos de rotação da alça bacteriológica, para se obter um esfregaço de forma oval, bem fino e uniforme;

6. Deixou-se secar nas proximidades da chama;

7. Fixou-se o esfregaço passando a lâmina (lado oposto ao esfregaço) 5 vezes na chama do bico de Bunsen (rapidamente).

- Método de Coloração de Gram

1. Cobrir toda a lâmina com solução cristal violeta (corante roxo), aguardar um minuto (Figura 3);

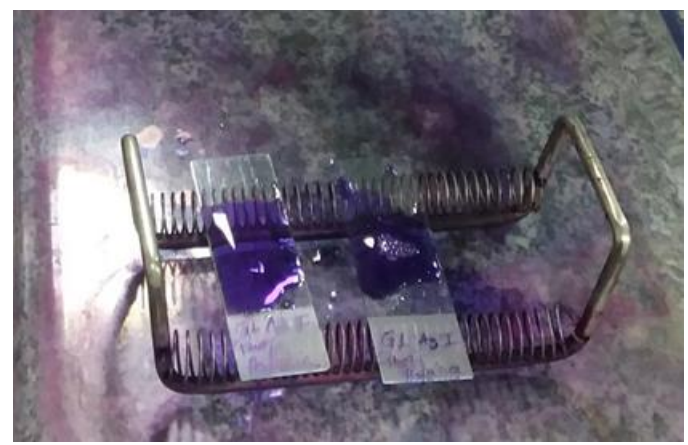

Figura 3: Lâmina coberta com solução cristal violeta.

2. Lavar rapidamente em água destilada;

3. Cobrir a lâmina com solução de lugol (mordente) por um minuto;

4. Lavar em água destilada;

5. Inclinar a lâmina e gotejar álcool-acetona ou álcool absoluto (cerca de 15 segundos);

6. Lavar a lâmina rapidamente em água corrente;

7. Cobrir com fucsina de gram e aguardar 30 segundos;

8. Lavar a lâmina em água destilada e secar (sem esfregar) (Figura 4); 


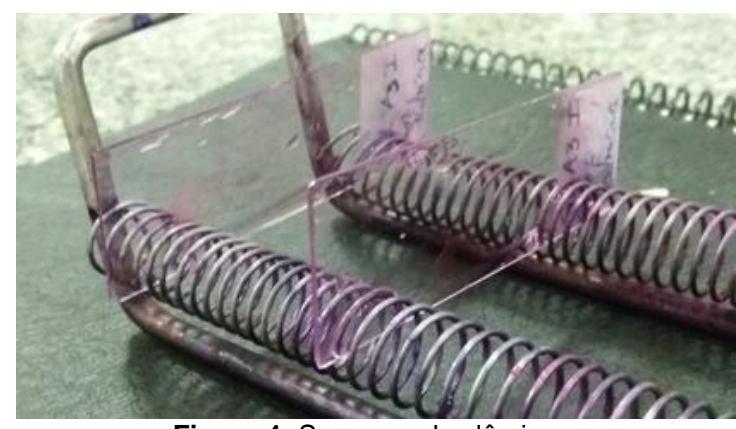

Figura 4: Secagem das lâminas.

9. Colocar uma gota de óleo de cedro sobre a lâmina e observar em objetiva de imersão (IOOX).

- Resultado

1. Bactérias Gram-positivas: roxo

2. Bactérias Gram-negativas: rosa/ vermelho.

Realizadas as duas coletas foi feita uma análise comparativa entre as amostras antes e após a desinfecção, para verificar qual solução foi mais eficaz na redução microbiológica nos cones de guta-percha utilizados como material obturador endodôntico. Inicialmente, realizou-se a análise estatística descritiva objetivando caracterizar a amostra. Em seguida, foram calculadas as frequências absolutas e percentuais quanto à presença de crescimento de microrganismos de acordo com os diferentes grupos experimentais. $O$ teste exato de Fisher foi aplicado para determinar diferenças significativas intergrupos (G1 X G2 X G3), ao passo que o teste de McNemar foi empregado para identificar diferenças significativas intragrupos (T0 X T1). O nível de significância foi fixado em $p<0,05^{8}$. Todas as análises foram realizadas usando o software IBM SPSS Statistics versão 20.0 e considerando um intervalo de confiança de $95 \%$.

Por se tratar de um estudo experimental, não envolvendo seres humanos ou animais não foi submetido ao Comitê de Ética em Pesquisa, porém respeitou-se as diretrizes e normas aprovadas pela Resolução 466/2012 do Conselho Nacional de Saúde.

\section{RESULTADOS}

A partir dos resultados obtidos no presente estudo evidenciou-se que as embalagens lacradas apresentaram insucesso na esterilização dos cones de guta-percha, constatado a partir dos dados da Tabela 2 . Tanto o $\mathrm{NaOCl} 2,5 \%$ quanto a Clorexidina $2 \%$ demonstraram efetividade satisfatória, em mais de $75 \%$ dos casos, na desinfecção dos cones de guta-percha. $O$ grupo controle não apresentou crescimento microbiológico.

Ao final do experimento foram identificados os seguintes resultados para os grupos: G1-ausência de crescimento de microrganismos $(0,0 \%)$ G2-presença de crescimento de bacilos Gram - (13,3\%); G3presença de crescimento de cocos Gram + $(13,3 \%)$ e de bacilos Gram - $(20,0 \%)$. No entanto, estas diferenças não foram estatisticamente significativas ( $p$-valores $>0,05$ ).

Tabela 2. Avaliação quanto à presença de crescimento de microrganismos de acordo com os diferentes grupos experimentais

\begin{tabular}{|c|c|c|c|}
\hline \multirow{3}{*}{ VARIÁVEIS } & \multicolumn{3}{|c|}{ GRUPOS } \\
\hline & G1 & G2 & G3 \\
\hline & n (\%) & n (\%) & n (\%) \\
\hline \multicolumn{4}{|l|}{ Cocos Gram + } \\
\hline To & $1(6,7)^{\mathrm{Aa}}$ & $\mathrm{O}(\mathrm{o}, \mathrm{O})^{\mathrm{Aa}}$ & $\mathrm{O}(\mathrm{O}, \mathrm{O})^{\mathrm{Aa}}$ \\
\hline T1 & $\mathrm{O}(\mathrm{O}, \mathrm{O})^{\mathrm{Aa}}$ & $\mathrm{O}(\mathrm{O}, \mathrm{O})^{\mathrm{Aa}}$ & $2(13,3)^{\mathrm{Aa}}$ \\
\hline \multicolumn{4}{|l|}{ Bacilos Gram + } \\
\hline To & $\mathrm{O}(0,0)^{\mathrm{Aa}}$ & $\mathrm{O}(\mathrm{O}, \mathrm{O})^{\mathrm{Aa}}$ & $\mathrm{O}(\mathrm{O}, \mathrm{O})^{\mathrm{Aa}}$ \\
\hline T1 & $\mathrm{O}(\mathrm{O}, \mathrm{O})^{\mathrm{Aa}}$ & $\mathrm{O}(\mathrm{O}, \mathrm{O})^{\mathrm{Aa}}$ & $\mathrm{O}(\mathrm{O}, \mathrm{O})^{\mathrm{Aa}}$ \\
\hline \multicolumn{4}{|l|}{ Bacilos Gram - } \\
\hline To & $1(6,7)^{\mathrm{Aa}}$ & $\mathrm{O}(\mathrm{O}, \mathrm{O})^{\mathrm{Aa}}$ & $1(6,7)^{\mathrm{Aa}}$ \\
\hline T1 & $\mathrm{O}(\mathrm{O}, \mathrm{O})^{\mathrm{Aa}}$ & $2(13,3)^{\mathrm{Aa}}$ & $3(20,0)^{\mathrm{Aa}}$ \\
\hline \multicolumn{4}{|l|}{ Leveduras } \\
\hline To & $\mathrm{O}(0,0)^{\mathrm{Aa}}$ & $\mathrm{O}(\mathrm{O}, \mathrm{O})^{\mathrm{Aa}}$ & $\mathrm{O}(\mathrm{O}, \mathrm{O})^{\mathrm{Aa}}$ \\
\hline T1 & $\mathrm{O}(\mathrm{O}, \mathrm{O})^{\mathrm{Aa}}$ & $\mathrm{O}(\mathrm{O}, \mathrm{O})^{\mathrm{Aa}}$ & $\mathrm{O}(\mathrm{O}, \mathrm{O})^{\mathrm{Aa}}$ \\
\hline \multicolumn{4}{|l|}{ Outros } \\
\hline To & $\mathrm{O}(0,0)^{\mathrm{Aa}}$ & $\mathrm{O}(0,0)^{\mathrm{Aa}}$ & $\mathrm{O}(0,0)^{\mathrm{Aa}}$ \\
\hline T1 & $\mathrm{O}(\mathrm{O}, \mathrm{O})^{\mathrm{Aa}}$ & $\mathrm{O}(\mathrm{O}, \mathrm{O})^{\mathrm{Aa}}$ & $\mathrm{O}(\mathrm{O}, \mathrm{O})^{\mathrm{Aa}}$ \\
\hline
\end{tabular}

Nota. Letras maiúsculas comparam valores na horizontal (avaliação intergrupo) e letras minúsculas comparam valores na vertical (avaliação intragrupo). Letras iguais sugerem ausência de diferenças estatisticamente significativas $(p>0,05)$.

No grupo 1, grupo controle, houve crescimento microbiológico apenas na fase inicial, podendo ser observado na Figura 5(A e B), pode-se observar as colônias de microrganismos que estavam presentes nas placas A2 e A8.

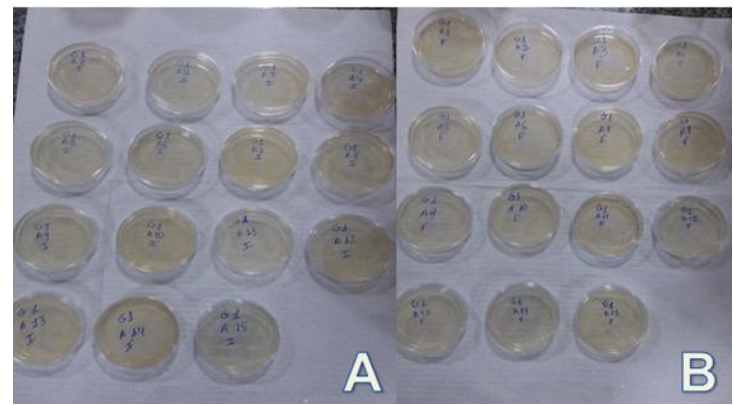

Figura 5: Em A Grupo 1 Inicial e em B Grupo 1 Final

No grupo 2 não houve qualquer tipo de crescimento microbiológico na fase inicial, podendo ser observado na Figura $6 \mathrm{~A}$. Apenas na fase final (Figura 6B) foi possível observar que houve crescimento microbiano nas amostras A11 e A13.

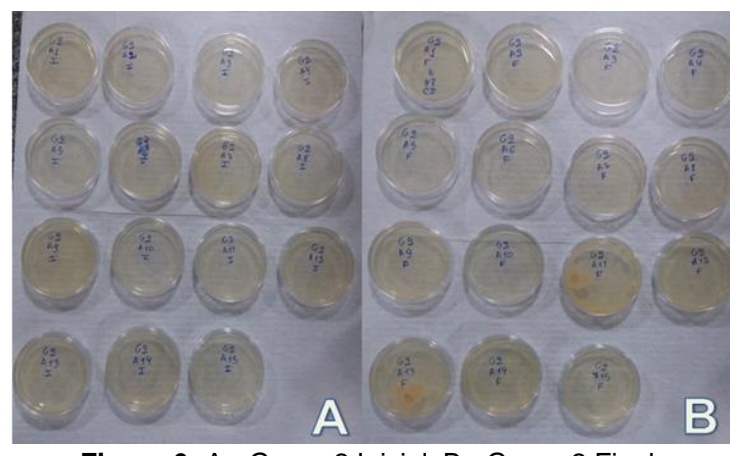

Figura 6: A - Grupo 2 Inicial ;B - Grupo 2 Final. 
No grupo 3 houve crescimento microbiológico tanto na fase inicial como na fase final (Figura 7A e B).

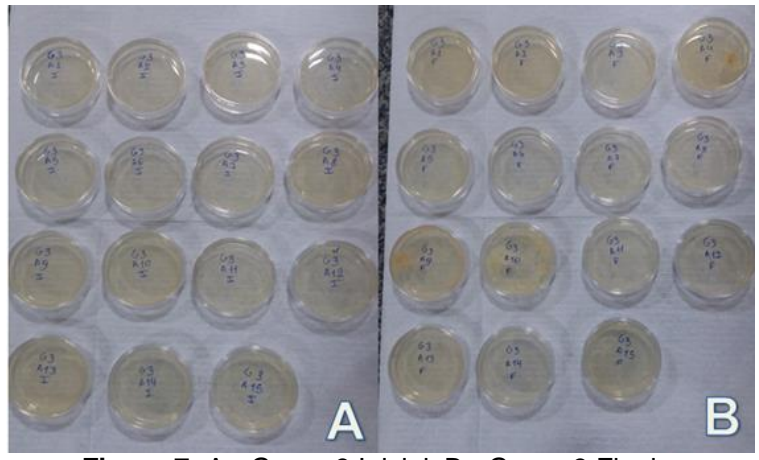

Figura 7: A - Grupo 3 Inicial; B - Grupo 3 Final.

$\mathrm{Na}$ Figura 8, pode-se observar somente as amostras contaminadas no grupo 3 .

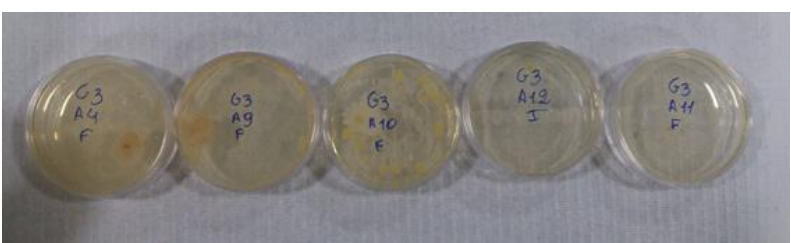

Figura 8: Amostras contaminadas do grupo 3.

Ainda, ao microscópio optico com aumento de $100 x$ pode se observar 0 crescimento microbiano na Figura $9(\mathrm{~A}$ e $\mathrm{B})$.

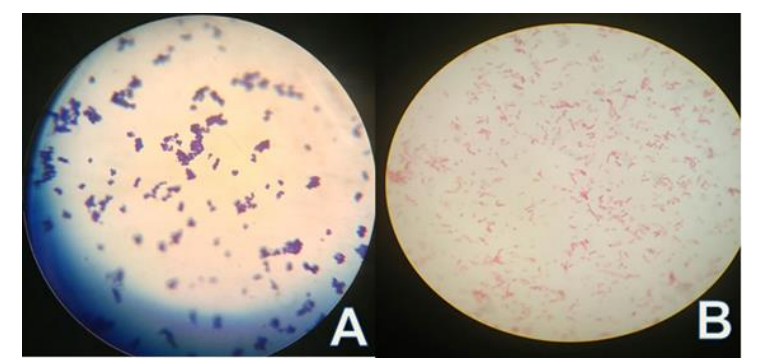

Figura 9: A - Crescimento de Cocos Gram +, ao microscópio de óptico com aumento de 100x. B - Crescimento de Bacilos Gram Negativo, ao microscópio de óptico com aumento de 100x.

\section{DISCUSSÃO}

Na prática endodôntica, a eliminação ou redução significativa de microorganismos do canal radicular por meios químicos e mecânicos é uma das características cruciais para 0 sucesso do tratamento. Cuidados devem ser tomados durante este procedimento para evitar a contaminação dos materiais de preenchimento para evitar a contaminação do canal radicular.

A guta-percha, por suas múltiplas propriedades, tem demonstrado ser um material muito versátil na endodontia e representa o padrão atual de obturação dos condutos radiculares. Entretanto a guta-percha utilizada com um cimento constitui uma barreira muito susceptível a uma possível migração microbiana ${ }^{9}$.

A desinfecção age na eliminação dos microorganismos, diferentemente do processo de esterilização. É importante a desinfecção dos cones de guta-percha para manter a cadeia asséptica durante todo o tratamento endodôntico, visto que o canal já foi limpo e modelado para o preparo químico e mecânico. $\mathrm{Na}$ Endodontia as técnicas de assepsia são mais comumente efetuadas, através de agentes químicos os quais são também utilizados para evitar a introdução de microorganismos nos canais radiculares contra a contaminação durante a terapia endodôntica ${ }^{9}$.

$\mathrm{Na}$ obturação dos canais radiculares, os cones de guta-percha ficam em íntimo contato com o periápice, assim, estes devem estar livres de microorganismos. Segundo Gahyva e Siqueira $^{10}$ sabe-se que existe a possibilidade destes virem contaminados em suas embalagens lacradas ou contaminados durante o seu manuseio. Ademais, por ser a gutapercha um material termoplástico que não pode ser submetido ao método de esterilização, os cones de guta-percha devem ser submetidos à soluções de descontaminação. Resultado também apresentado no presente estudo onde, na coleta inicial, nos Grupos G1(Controle) e G3 (Clorexidina $2 \%$ ) houve crescimento microbiano.

$\mathrm{Na}$ metodologia do presente estudo utilizou-se a técnica de Maki para plaqueamento e contagem de unidades formadoras de colônias (UFC), a qual segundo Maki et al. ${ }^{11}$ consiste do rolamento da ponta (segmento) do cateter em superfície de ágar suplementado com $5 \%$ de sangue de carneiro (AS). Após 72 horas de incubação, todas as placas foram inspecionadas quanto ao crescimento de microrganismos.

O Ágar Mueller Hinton foi o meio de cultura escolhido para a contaminação da gutapercha, considerando sua capacidade de ser um meio favorável ao cultivo de bactérias de difícil acesso, recomendado para a realização de antibiograma (teste de sensibilidade) pela técnica de difusão, observando o crescimento de fungos e bactérias. Já que o Brain Heart Infusion $(\mathrm{BHI})$ só permite o crescimento bacteriano.

Cardoso et al. ${ }^{12}$ testaram o hipoclorito de sódio a $1 \%$ e mostraram que essa solução seria eficiente em um tempo de contato de 5 minutos, no entanto, Rocha et al. $^{13}$ demonstraram que essa solução é capaz de desinfetar num tempo a partir de 1 minuto. Por outro lado, o mesmo estudo de Cardoso et al. ${ }^{12}$ pode ser confirmado quando, neste, se encontrou eficácia do Hipoclorito de Sódio 1\% e Clorexidina 2\% na desinfecção de cones contaminados por E.faecalis.

Fagundes et al. ${ }^{4}$ verificaram a eficiência de diferentes soluções na descontaminação de 
cones de guta-percha expostos ao Enterococcus faecalis. Utilizaram-se 80 cones, separados em 8 grupos (10 cones cada). Foram contaminados 70 cones com Enterococcus faecalis, e, depois, os grupos sofreram descontaminação: G1: álcool a 70\%, G2: álcool a $70 \%$ + iodo a 1\%, G3: álcool a $70 \%$ + clorexidina a 4\%, G5: $\mathrm{NaOCl}$ a 2,5\%, G6: $\mathrm{NaOCl}$ a $5,25 \%$, G7: solução salina, G8: não foi contaminado e não sofreu descontaminação (controle). Os cones foram mantidos nas soluções por 1 e 5 minutos.

Com base nos autores supracitados, no tempo de um minuto, houve crescimento bacteriano nos grupos 1, 2, 5 e 7. Porém, esses resultados divergem dos encontrados no estudo de Rocha et al. ${ }^{13}$ pois o álcool a $70 \%$ e o NaOCl a $2,5 \%$, no tempo de um minuto, foram capazes de impedir o crescimento bacteriano, dispensando qualquer tipo de associação de substâncias para potencializar o seu efeito. No entanto, este estudo mostrou que o $\mathrm{NaOCl} 2,5 \%$ foi eficaz na descontaminação dos cones de guta-percha, após 3 minutos. Mesmo havendo crescimento microbiológico em 2 amostras, ele foi eficaz, pois as diferenças do ponto de vista estatístico não foram significativas.

Das soluções capazes de dissolver tecidos necróticos, a mais utilizada é a de hipoclorito de sódio, por possuir triplo modo de ação: habilidade de dissolução de tecido necrótico, atribuída a sua alta alcalinidade; propriedade bactericida, relacionada com a formação do ácido hipocloroso pela liberação de cloro da solução; e saponificação de gorduras. Entre as alternativas ao hipoclorito de sódio está o gluconato de clorexidina. Este tem se mostrado um agente antimicrobiano efetivo no interior dos canais radiculares, com potencial para ser empregado como irritante ou medicamento intracanal. Tem indicação também em casos de rizogênese incompleta ou de hipersensibilidade ao hipoclorito de sódio, uma vez que apresenta relativa ausência de toxicidade. A clorexidina pode ser encontrada sob a forma líquida (solução aquosa) ou gel em concentrações que variam de $0,2 \%$ a $2 \%{ }^{14}$.

No estudo realizado por Pinheiro ${ }^{15}$ a clorexidina $2 \%$ demonstrou ineficiência, pois todas as amostras ficaram turvas, evidenciando presença bacteriana nos cones. Já no presente estudo a clorexidina $2 \%$ demonstrou efetividade satisfatória na descontaminação dos cones de guta-percha em um período de tempo de apenas 3 minutos.

Prado et al. ${ }^{5}$ mostrou que a clorexidina $2 \%$ pode ser a melhor opção para desinfecção dos cones de guta percha antes da obturação do sistema de canais radiculares. Porém, no presente estudo, embora a clorexidina $2 \%$ tenha sido eficaz, constatou-se que o hipoclorito de sódio $2,5 \%$ foi mais eficaz na maioria dos casos.

$\mathrm{O}$ estudo de Rocha et al. ${ }^{13}$ mostraram que a clorexidina nas concentrações de $0,12 \%$ e $2 \%$ foram capazes de desinfetar os cones de guta-percha, o que confirma os achados de Redmerski et al. ${ }^{16}$ que investigaram a eficácia da solução aquosa e do detergente de diguclonato de clorexidina $2 \%$ e constataram que as duas substâncias foram capazes de descontaminar cones de guta-percha contaminados com E.faecalis.

Silva e Santos ${ }^{17}$ avaliaram a esterilidade dos cones de guta-percha e constataram que os cones não estavam contaminados nas embalagens, no entanto afirmaram que, apesar de aparente desnecessária desinfecção, o transporte e a manipulação exagerada podem levar à contaminação, sendo a desinfecção uma medida de segurança para a obturação do canal radicular. Porém, no presente estudo, mostrouse que as embalagens lacradas apresentavam contaminação dos cones de guta-percha.

CONCLUSÃO

Com base nos resultados obtidos pode-se concluir que é necessária a desinfecção dos cones de guta-percha apesar de serem conduzidos em condições assépticas; ambas as soluções desinfectantes foram eficazes na descontaminação prévia dos cones de guta-percha.

REFERÊNCIAS

1. Amaral G, Carraz R, Freitas LF, Fidel SR, Castro AJR. Efetividade de três soluções na descontaminação de cones de guta-percha e de resilon. Rev bras odontol. 2013;70(1):54-8.

2. Siqueira JRJF, Rôças IN, Lopes HP, Alves FRF, Oliveira JCM, Armada L, et al. Princípios biológicos do tratamento endodôntico de dentes com polpa viva. Rev bras odontol. $2011 ; 68(2) ; 161-65$.

3. Lopes HP, Siqueira Jr JF. Endodontia: biologia e técnica. 4 ed. Rio de Janeiro: Elsevier; 2015.

4. Fagundes FS, Leonardi DP, Baratto Filho F, Haragushiku GA, Tomazinho LF, Tomazinho $\mathrm{PH}$. Eficiência de diferentes soluções na descontaminação de cones de guta-percha expostos ao Enterococus faecalis. RSBO. 2005;2(2):7-11.

5. Prado M, Gusman H, Gomes BP, Simão RA. The importance of final rinse after disinfection of gutta-percha and Resilon cones. Oral surg oral med oral pathol oral radiol endod. 2011;111(6):e21-4.

6. Faul F, Erdfelder E, Lang AG, Buchner A. 
G*Power 3: a flexible statistical power analysis program for the social, behavioral, and biomedical sciences. Behav Res Methods. 2007;39(2):175-91.

7. Soares MM, Ribeiro MC. Microbiologia prática roteiro e manual: bactérias e fungos. São Paulo: Atheneu; 2002.

8. Larson R, Farber B. Estatística Aplicada. 6 ed. São Paulo: Pearson Prentice Hall; 2016.

9. Benítez SR, Guelfand CS. Uso clínico del Resilon: um nuevo material adhesivo para la obturacíon de los conductos radiculares. Gaceta dental: Industria y profesiones. 2006;167:92-108.

10. Gahyva SM, Siqueira Junior JF. Avaliação da contaminação de cones de gutapercha disponíveis comercialmente. J Bras Endo/Pério. 2001;4(6):193-95.

11. Maki DG, Weise CE, Sarafin HW. A semiquantitative culture method for identifying intravenous-catheter-related infection. $\mathrm{N}$ Engl J Med. 1977;296(23):1305-9.

12. Cardoso Celso L, Redmerski R, Bittencourt NLR, Kotaka CR. Effectiveness of different chemical agents in rapid decontamination of gutta-percha cones. Braz J Microbiol. 2000;31(1):67-71.

13. Rocha EALS, Limeira FIR, Carvalho AVOR, Santos KSA, Medeiros ACD. Avaliação da eficácia de diversas substâncias químicas na descontaminação de cones de guta-percha. Odontol clín-cient. 2013;12(1):35-8.

14. Michelotto ALC, Andrade BM, Silva Júnior JA, Sydney GB. Clorexidina na terapia endodôntica. RSBO. 2008;5(1):125-39.

15. Pinheiro GR. Análise comparativa da eficiência dos agentes químicos na desinfecção e esterilização dos cones de guta-percha estudo in vitro [Monografia]. Campina Grande: Universidade Estadual da Paraíba; 2012.

16. Redmerski R, Bulla JR, Moreno T, Garcia LB, Cardoso CL. Disinfection of gutta-percha cones with chlorhexidine. Braz J Microbiol. 2007; 38(4):649-55.

17. Silva LJG, Santos ACM. Esterilidade de cones de guta-percha. Rev biociênc. 2002;8(1):71-5.

\section{CONFLITO DE INTERESSES}

Os autores declaram não haver conflitos de interesse

\section{AUTOR PARA CORRESPONDÊNCIA}

\section{José Henrique de Araíjo Cruz}

Rua Paulo Diogenes, número 57 - Centro 59990-000 Rafael Fernandes - RN, Brasil Telefone: (83) 99625-0125.

E-mail: henrique_araujo1992@hotmail.com

Submetido em 15/08/2019 Aceito em 23/10/2020 